\title{
The Association Between Motor Proficiency and Performing Recreational and Leisure Activities in School for Children with Autism Spectrum Disorder
}

\author{
Mahsa Kheirollahzadeh ${ }^{1}$, Mehdi Alizadeh Zarei $^{1 *}$, Malek Amini ${ }^{1}$, Faezeh Dehghan Tarzjani ${ }^{2}$
}

1. Department of Occupational Therapy, School of Rehabilitation, Iran University of Medical Sciences, Tehran, Iran

2. Department of Neuroscience, School of New Technologies, Iran University of Medical Sciences, Tehran, Iran

\begin{tabular}{l} 
Article Info \\
\hline Received: $2018 / 01 / 17$ \\
Accepted: $2018 / 03 / 15$ \\
Published Online: 2018/10/29 \\
DOI: \\
10.30699/fdisj.01.2.1 \\
How to Cite This Article \\
Kheirollahzadeh M, Al- \\
izadeh Zarei M, Amini M, \\
Dehghan Tarzjani F. The \\
Association Between Motor \\
Proficiency and Performing \\
Recreational and Leisure \\
Activities in School for Chil- \\
dren with Autism Spectrum \\
Disorder. Function and Disa- \\
bility Journal.2018 (spring). \\
Vol 1.No2 Pages: 1-8.
\end{tabular}

Use your device to scan and read the article online

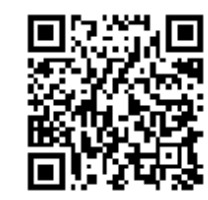

\begin{abstract}
Background and Objectives: Performing recreational and leisure activities are an important part of children's school function, including children with autism spectrum disorder (ASD). The purpose of this study was to examine the association between motor proficiency, performing recreational, and leisure activities in school for the children with autism spectrum disorder.
\end{abstract}

Methods: In this cross-sectional study, 52 students with autism spectrum disorder aged 7-12 years old were selected by available sampling method and the students with co morbidity were excluded from the study. Data were collected using a school function assessment (SFA) and the Bruininks-Oseretsky test of motor proficiencySecond Edition (BOTMP-2).

Results: The results of Pearson correlation coefficient showed that there was a significant positive linear relationship with moderate strength between performing recreational and leisure activities and components of motor proficiency, including gross motor skills $(P=0.001, \mathrm{r}=0.41)$, upper limb coordination $(P=0.000, \mathrm{r}=0.44)$, and fine motor skills $(P=0.00, \mathrm{r}=0.58)$. Also, the results of multiple linear regression model indicated that only the fine motor skills as one of the components of motor proficiency had the ability to predict performing recreational and leisure activities $(\beta=0.5, P=$ 0.002).

Conclusion: The results of this study revealed that there was a relationship between performing recreational, leisure activities, and motor proficiency and the highest correlation was observed with fine motor skills, upper limb coordination, and gross motor skills, respectively. Also, fine motor skills had a moderate predictive ability. Thus, in order to improve student's function in their school, perceptual motor interventions would be an important part of their treatment program.

Keywords: Recreational, Leisure activities, Motor skills, Activities of daily living, Autism Spectrum Disorder (ASD) Autism Spectrum Disorder (ASD)

Mehdi Alizadeh Zarei, Department of Occupational Therapy, School of Rehabilitation Sciences, Iran University of Medical Sciences, Tehran, Iran. Email: mehdii.alizadeh@yahoo.com Tel;+98-2122228051

Corresponding information:

Copyright (C) 2018, Function and Disability Journal. This is an open-access article distributed under the terms of the Creative Commons Attribution-noncommercial 4.0 International License which permits copy and redistribute the material just in noncommercial usages, provided the original work is properly cited.

\section{Introduction}

Performing recreational and leisure activities is considered as one of the areas of participation in the international classification of function, disability and health (ICF).In the ICF, recreation is defined as common activities such as games, sports, theater, arts and tourism. Participation in recreational and leisure activities is essential for the health and development of the children. The participation of children in appropriate recreations is very effective on their physical and mental health. Some studies have shown the impact of recreational and leisure activities on the reduction of behavioral and emotional problems in children (Potvin $\mathrm{M}$ et al. , 2013).

Promoting performance of the recreation and leisure activities in children with disabilities is also important (Murphy \& Carbone, 2008). Recreational and leisure activity is one of the subject are as listed in 
the special education program for individuals with disabilities and should be a part of the individualized education program (IEP) for the students with special needs (Schultheis S, Boswell B, and Decker J 2016).Prevention of recreational and leisure activities will deprive children with disabilities of the opportunity for physical and psychosocial experiences. As a result, they will be deprived of the development of basic movement patterns, psychomotor competency, psychosocial awareness, learning, joining the community, and fitness (Schleien S et al., 1987).

Performing recreational and leisure activities in children with autism spectrum disorder (ASD) is very limited and leads to reduction in satisfaction and quality of life (Law M et al., 2006).In their retrospective study, Billstedt et al (2011) showed that participation in recreational and leisure activities is the most effective factor in the quality of life from the viewpoint of adolescents and adults with autism(Billstedt E, Gillberg C, and Gillberg C, 2011).According to Potvin et al, the recreations of children with ASD differed from peers in terms of social aspects, diversity, and locations, but did not differ in terms of tendency to recreation and enjoying (Potvin $\mathrm{M}$ et al. 2013).Some studies have examined the reasons of restraint in performing recreational and leisure activities in children with ASD. The factors such as communication disorders, social deficits, stereotyped behaviors, motor skills and non-adaptive behaviors have been suggested as barriers to the participation in recreation (Potvin M et al., 2013).

The motor activity limitations in children with ASD will deprive them of the opportunity to interact and learn (Downey R and Rapport M, 2012; Staples K and Reid G, 2010). The greater the severity of autism disorder is, the weaker the motor skills are. This lessense the level of participation and enjoyment of recreational and leisure activities (majnemer A et al. 2008; Eversole $\mathrm{M}$ et al., 2015). According to the study conducted by Must et al, more than $60 \%$ of the children with ASD had difficulty in performing motor activities and needed to be monitored (Must A et al., 2015).The study by Pan et al. showed a marked difference in performing motor activities in school between children with ASD and their peers (Pan CH, 2008). It seems that the study of limiting factors of recreational and leisure activities in children with ASD have been neglected despite their important role in the quality of life, development and learning (Potvin M, Prelock P, and Snider L, 2008). Therefore, in this study, the association between motor proficiency and performing recreational and leisure activities was examined, which has not been adequately addressed so far.

\section{Materials and Methods}

\section{Participants}

The participants were 52 students aged $7-12$ years old with diagnosis of ASD in high functioning level. The inclusion criteria were: the diagnosis of ASD by the Gilliam Autism Rating Scale-2 (GARS-2) or diagnosis confirmed by a child psychiatrist, lack of co morbid psychiatric disorders such as attention deficit hyperactivity disorder (ADHD), anxiety, and depression based on the child symptom inventory -4 (CSI-4), the age between 7 and 12 years, and studying at special schools for autistic children.

\section{Procedure}

The present study was a comparative cross-sectional study. The research project was approved and a certificate in ethics (ID number: IR.IUMS. REC1395.9411255002) was issued by Iran University of Medical Sciences. Then, three schools specifically for the autistic children; Peyk-e-honar, Beshaarat and payambar-e-azam, were visited in the three districts of Tehran. With the cooperation of the schools principals and by referring to the data files, the students who were matched to inclusion in term of age were selected. The parents of the students were invited to participate in the study. They received a written consent form for the participation in the research, CSI-4, ASSQ and GARS questionnaire to fill out. The parents were asked to complete the questionnaires and return them to the school principal within 3 days. During this time, the researcher was available to answer any question through telephone calls. After assessing the completed CSI-4, ASSQ and GARS questionnaire, 67 students were subjected to ASD diagnosis with high functioning level, 
and 15 of them were excluded from the study because of the ADHD co morbidity. Eventually, 52 children were included in the study. The Bruininks-Oseretsky test of motor proficiency (BOTMP-2) was conducted in a room of the school by maintaining the standards of the test regarding the space and appropriate ventilation. The researcher for four students per day performed the motor test. Initially, subtests of gross motors were assessed. If the child had enough attention to continue the test. The subtests of fine motors and coordination would also be evaluated. Otherwise, the continuation of the test would be postponed to another day.

\section{Measurement tools}

1. School Function Assessment (SFA): Coster et al. in the United States developed SFA in 1998. The validity and reliability of this test have generally been verified. Moreover, they have been proven in the Iranian context as well. The Cronbach's alpha coefficient for the different parts of this tool was excellent $(0.84<$ alpha $<$ $0.99)$. The test-retest reliability of the test was good for the subtest of this tool $(0.85<$ ICC $<$ 0.99) (Ghorbani Kouhbanani N et al. 2018), (Shojaee $M$ et al. 2017). This tool is deemed as a comprehensive assessment tool for evaluating the function and participation of preschool students up to the sixth grade. The time required to complete the form is 45 minutes to 1 hour. The SFA includes 320 items categorized into three sections as follows: participation, task support, and activity performance. In the section related to the activity performance, the therapist can evaluate the students' participation in usual recreational activities occurring in school through 11 questions. Teachers, occupational therapists, speech and language pathologists, physiotherapists, teachers, and other support staff can complete the items. Each aforementioned group can answer the relevant items to them (Coster W et al 1998).

2. The Bruininks-Oseretsky test of motor proficiency - Second Edition (BOTMP-2): This is a norm-referenced test designed to assess mo- tor function of the children aged from 4 years 6 months to 14 years 6 months. The Complete Form of the BOTMP consists of 46 items, which are divided into eight subtests, and the BOTMP Short Form comprises a subset of 14 items of the BOTMP Complete Form and provides a brief survey of general motor proficiency. Bruininks (1987) has provided this test by modifying Oseretsky test of motor proficiency. Test-retest reliability was 0.87 and its validity was 0.84 . Performing the Complete Form of the BOTMP requires approximately 45 to 60 minutes and the BOTMP Short Form takes about 15 to 20 minutes. Each of the 8 subtests is designed to measure a specific aspect of motor development. Four of the subtests measure gross motor skills, one of the subtests assesses the motor coordination, and three of them evaluate fine motor skills (Bruininks RH 1978).

3. The Giliam Autism Rating Scale -Second Edition (GARS-2): The Gilliam Autism Rating Scale (Gilliam, 1995) is a tool for the diagnosis and screening of autism for individuals between the ages of 3 and 22. The GARS-2 consists of 56 items divided into 4 subscales: stereotyped behaviors, communication, social interaction, and developmental disorders. Each item uses a 4-point Likert scale (Never, Rare, Sometimes, Often).The total scores are converted to standard scores. The psychometric properties of the GARS-2 have been investigated in Iran. The cutoff point for the GARS-2 is 52, and the sensitivity and specificity are obtained $90 \%$ and $100 \%$, respectively. The reliability of this scale was also estimated using the Cronbach's alpha coefficient of 0.89 (Ahmadi SJ et al., 2011).

4. Autism spectrum screening questionnaire (ASSQ): The ASSQ was designed to assess the children aged 6 to 17 years old with normal intelligence to mild mental retardation, and is a screening measure (not a diagnostic measure). It was originally developed for Asperger Syndrome, later, it was also found suitable for other conditions on the Autism Spectrum. The ques- 
tionnaire used here is the High-Functioning Autism Spectrum Screening Questionnaire (ASSQ). It has 27 questions that are filled in by parents or teachers of children or adolescents. Test-retest reliability in 34 parents of autism spectrum group was obtained $(r=0.467)$. The content validity over 0.3 was assessed (Kasechi M et al., 2014).

5. Child symptom inventory $\mathbf{- 4}$ (CSI-4): This is a behavior rating scale that was first developed in 1984 to screen 18 emotional and behavioral disorders in children between the ages of 5 to 12 years old, and in 1994, the fourth edition of DSM-IV was revised and named to CSI-4. The CSI-4 has two forms for parents and for teachers. The parent form of the CSI-4 has 112 items, which is considered for 11 major groups and an additional group of behavioral disorders. The teacher form has 77 items that covers 9 major groups of behavioral disorders. The comments and the positive judgments of professionals related to the content of CSI-4 with the tested area has validated content validity of the questionnaire as a tool for identification and screening the behavioral and emotional disorders in children. Comparing the scores of categories of questionnaire with the psychiatric-based diagnosis, criterion validity was assessed and high sensitivity and specificity of most of the disorders of the questionnaire, particularly parents' questionnaire, suggests criterion validity of this instrument (Esmaeili M, 2007).

\section{Statistical analysis}

All data were analyzed using SPSS version 21. In this study, descriptive and analytical statistics including
One-Sample Kolmogorov-Smirnov Test were used to check the normality of the data. Considering the normality of the data, Pearson's correlation coefficient was used to describe the relationship and assess the difference in communication models between variables. Moreover, multiple linear regression model was used to investigate the role of motor proficiency in predicting the implementation of recreational and leisure activities.

\section{Results}

The participants in the study were boys aged 6-12 years (median 117 months) who were studying at preschool class through fifth grade. The results of Pearson's correlation coefficient and statistical analysis showed that there was a moderate significant relationship between motor proficiency and performing recreational and leisure activities, and the highest correlation was with fine motor skills $(P=0.00, \mathrm{r}=0.58)$, upper limb coordination $(P=0.00, \mathrm{r}=0.44)$ and gross motor skills $(P=0.001, \mathrm{r}=0.41)$, respectively. Moreover, the results of multiple linear regression model indicated that the independent variable of motor proficiency had the ability to predict $31 \%$ of the variation in the dependent variable of performing recreational and leisure activities (adjusted $\mathrm{R}$ square $=0.31$ ) . Regression coefficients $(\beta)$ showed that only fine motor skills as one of the components of motor proficiency had the ability to predict the implementation of recreational and leisure activities. It means that a standard deviation from fine motor skills would result in a 50\% standard deviation in the variable of performing recreational and leisure activities $(\beta=0.5, P=0.002)$.

Table 1. Pearson correlation and multiple linear regression model for dependent variable of performing recreational and leisure activities and independent variable of motor proficiency.

\begin{tabular}{|c|c|c|c|c|c|c|c|c|c|}
\hline \multicolumn{10}{|c|}{ performing recreational and leisure activities } \\
\hline & & $\begin{array}{l}\text { Pearson's } \\
\text { correlation } \\
\text { coefficient }\end{array}$ & $\begin{array}{c}\text { Significance } \\
\text { level }\end{array}$ & $\mathrm{R}$ & R square & $\begin{array}{l}\text { Adjusted } \\
\text { R square }\end{array}$ & $\begin{array}{c}\text { Significance } \\
\text { level of the } \\
\text { model }\end{array}$ & $\beta$ & $\begin{array}{c}\text { Significance } \\
\text { level }\end{array}$ \\
\hline \multirow{3}{*}{$\begin{array}{c}\text { motor } \\
\text { proficiency }\end{array}$} & gross motor skills & 0.41 & $0.001^{* *}$ & & & & & -0.09 & 0.68 \\
\hline & upper limb coordination & 0.44 & $0.00^{* *}$ & 0.59 & 0.35 & 0.31 & 0.00 & 0.21 & 0.34 \\
\hline & fine motor skills & 0.58 & $0.00^{* *}$ & & & & & 0.50 & 0.002 \\
\hline
\end{tabular}

** correlation is significant at the 0.01 level (1tailed) 


\section{Discussion}

The purpose of this study was to examine the association between motor proficiency, performing recreational, and leisure activities in school for children with autism spectrum disorder. In this study, motor proficiency was generally considered as a set including fine and gross motor skills, and upper limb coordination. In the gross motor skills, four subtests, i.e. running speed, agility, balance, bilateral coordination and strength were measured ; in the fine motor skills, three subtests, i.e. response speed, visual-motor control, and upper-limb speed and dexterity were measured. Recreational and leisure activities in school function assessment were 11 cases: including playing with moving equipment such as swings and see-saws, throwing and catching a big ball, playing with stable equipment at ground level such as slides and ladders, catching an accelerated ball, running over at least 6 $\mathrm{m}$ on a straight track, running without falling with a change in direction or speed, the ability to hopscotch, jumping rope, catching and throwing a small ball like a tennis ball, shooting a ball, throw or hit the target, and play with stable equipment at high level like a horizontal bar. Based on the obtained results, there was a moderate significant relationship between motor proficiency and performing recreational and leisure activities in school. In other words, whatever motor proficiency in children with ASD was better; they were more successful in performing recreational and leisure activities. Moreover, the highest correlation of performing recreational and leisure activities in school was with fine motor skills, upper limb coordination, and gross motor skills, respectively. In addition, fine motor skills as one of the components of motor proficiency had the ability to predict the implementation of recreational and leisure activities. This means that the deficiency in fine motor skills at preschool ages could limit performing recreational and leisure activities in school, and whatever fine motor skills of the children at preschool ages improved, they would face less difficulty in performing recreational and leisure activities in school. Performing recreational and leisure activities in school would lead to communica- tion and interaction with teachers and other students. As Liu and Macdonald also showed in their study on the children with ASD, the deficiency in motor proficiency, especially the object-control skill, which is a component of fine motor skills, would limit social interactions(MacDonald M, Lord C, and Ulrich D, 2013; Liu T et al., 2014).Given that fine motor skills could predict the implementation of recreational and leisure activities, therapy interventions to improve fine motor skills would prevent the presence of limitation in performing recreational and leisure activities in school. The findings from Barnett et al. study also confirmed that the development of motor skills in childhood is one of the key interventions for promoting motor activities in the future (Barnett L et al., 2009). In addition, according to the study conducted by Sheilds, motor skill training for children with disabilities facilitates their participation in everyday motor activities, including recreational and leisure activities (Shields N, Synnot A, and Barr M, 2012). Thus, occupational therapists by developing a treatment planning based on the Bruininks-Oseretsky test of motor proficiency can provide the basis for more participation of the children with ASD in performing recreational and leisure activities.

\section{Limitations of the Study}

The limitation of the present study was the lack of access to the same number of students per grade.

\section{Conclusion}

The results of this study showed a moderate significant relationship between motor proficiency and performing recreational and leisure activities in school. That means, better motor skills in children with ASD help them for better performing in recreational activities. In other word, whatever motor proficiency in children with ASD was better; they would be more successful in performing recreational and leisure activities. In addition, the highest correlation of performing recreational and leisure activities in school was observed with fine motor skills, upper limb coordination, and gross motor skills, respectively. Moreover, fine motor skills as one of the components of the motor proficiency had the ability to predict the 
implementation of recreational and leisure activities. This means that the deficiency in fine motor skills at preschool ages could limit performing recreational and leisure activities in school. Recreational and leisure activities as a part of the children's school performance, including children with ASD have been neglected despite their important role in their satisfaction and quality of life. Thus, in order to improve the students function in their school, perceptual motor interventions would be an important part of their treatment program.

\section{References}

Ahmadi, Sj., Safari, T., Hemmatian, M., And Khalili Z. (2011).The Investigation Of Psychometry Of Giliam Autism Rating Scale. Journal Of Cognitive And Behavioral Science. 1, 87-104.

Barnett, L., Beurden, E., Morgan, P., Brooks, L., And Beard J. (2009). Childhood Motor Skill Proficiency As A Predictor OfAdolescent Physical Activity. Journal Of Adolescent Health, 44, 252-59.

Billstedt, E., Gillberg, Ic., And Gillberg, C. (2011). Aspects Of Quality Of Life In Adults Diagnosed With Autism In Childhood. Autism SagePublications And The National Autistic Society, 15, 7-20.

Bruininks, Rh. (1978). Bruininks Oseretsky Test Of Motor Proficiency:Examiner's Manual: American Guidance Service Circle Pines.

Coster, W., et al. (1998). School Function Assessment User's Manual. United States. Sargent College Of Health And Rehabilitation Science, Boston University.

Downey, R., \& Rapport, M. J. K. (2012). Motor activity in children with autism: a review of current literature. Pediatric Physical Therapy, 24(1): 2-20.

Eversole, M., Collins, D. M., Karmarkar, A., Colton, L., Quinn, J. P., Karsbaek, R., ... \& Hilton, C. L. (2016). Leisure activity enjoyment of children with autism spectrum disorders. Journal of autism and developmental disorders, 46(1), 10-20.

Kasehchi, M., Behnia, F., Mirzaee, H., Rasafyani, M., Farzi, M., \& Gharib, M. (2013). Validity and reliability of Persian version of high-functioning autism spectrum screening questionnaire age 7-12. Pajouhan Scientific

\section{Acknowledgement}

This study was obtained by the Master's thesis in occupational therapy in Iran University of Medical Sciences (ID number: IR.IUMS.REC1395.9411255002). We would like to thank the parents of participants and the staff at schools of Peik-e-Honar and Besharat and Payambar-e-Azam who collaborated with us on sampling of this study.

\section{Conflict of interest statement}

Authors declared no conflict of interest.

Jour-nal, 12(1), 45-54.

Kouhbanani, N. G., Zarei, M. A., Lajevardi, L., Rahimzadegan, H., \& Shojaei, A. (2018). The Reliability of the Persian Version of the School Function Assessment in Iranian Students 6 to 12 Years Old in Tehran Schools. Mid-dle East Journal of Rehabilitation and Health, 5(1):e64364.

Law, M., King, G., King, S., Kertoy, M., Hurley, P., Rosenbaum, P., \& Hanna, S. (2006). Patterns of participation in recreational and leisure activities among children with complex physical disabilities. Developmental medicine and child neurology, 48(5), 337-342.

Liu, T., Hamilton, M., Davis, L., \& ElGarhy, S. (2014). Gross motor performance by children with autism spectrum disorder and typically developing children on TGMD-2. Journal of Child and Adolescent Behaviour.

MacDonald, M., Lord, C., \& Ulrich, D. A. (2013). The relationship of motor skills and social communicative skills in school-aged children with autism spectrum disorder. Adapted Physical Activity Quarterly, 30(3), 271282.

Majnemer, A., Shevell, M., Law, M., Birnbaum, R., Chilingaryan, G., Rosenbaum, P., \& Poulin, C. (2008). Partic-ipation and enjoyment of leisure activities in school-aged children with cerebral palsy. Developmental Medicine \& Child Neurology, 50(10), 751-758.

Mohammad, E. E. (2007). Adaptation and standardization of child symptom inventory-4 (CSI-4).

Murphy, N. A., \& Carbone, P. S. (2008). Promoting the participation of children with disabilities in sports, recrea-tion, and physical activities. Pediatrics, 121(5), 
1057-1061.

Must, A., Phillips, S., Curtin, C., \& Bandini, L. G. (2015). Barriers to physical activity in children with autism spectrum disorders: relationship to physical activity and screen time. Journal of Physical Activity and Health, 12(4), 529-534.

Pan, C. Y. (2008). School time physical activity of students with and without autism spectrum disorders during PE and recess. Adapted Physical Activity Quarterly, 25(4), 308-321.

Potvin, M. C., Prelock, P. A., \& Snider, L. (2008). Collaborating to support meaningful participation in recreational activities of children with autism spectrum disorder. Topics in Language Disorders, 28(4), 365-374.

Potvin, M. C., Snider, L., Prelock, P., Kehayia, E., \& Wood-Dauphinee, S. (2013). Recreational participation of children with high functioning autism. Journal of Autism and Developmental Disorders, 43(2), 445-457.

Schleien, S., Krotee, M., Mustonen, T., Kelterborn, B., $\&$ Schermer, A. (1987). The effect of integrating children with autism into a physical activity and recreation setting. Therapeutic Recreation Journal, 21(4), 52-62.

Schultheis, S. F., Boswell, B. B., \& Decker, J. (2000). Successful physical activity programming for students with autism. Focus on Autism and Other Developmental Disabilities, 15(3), 159-162.

Shields, N., Synnot, A. J., \& Barr, M. (2012). Perceived barriers and facilitators to physical activity for children with disability: a systematic review. Br J Sports Med, 46(14), 989-997.

Shjaee, M., Alizadeh Zarei, M., \& Hassani Mehraban, A. (2017). Translation, face and content validity of the persian version of school function assessment. Middle East Journal of Rehabilitation and Health Studies, 4(4), e14594.

Staples, K. L., \& Reid, G. (2010). Fundamental movement skills and autism spectrum disorders. Journal of autism and developmental disorders, 40(2), 209-217. 
Function and Disability Journal ISSN: 2588-6304

$$
\text { مقالأ يزوهشى }
$$

\section{ييوستگى بين مهارتهاى حركتى و انجام فعاليتهاى خلاقانه و تفريحى در مدرسه براى كودكان مبتلا به اختلال طيف اوتيسم}

\section{مهرسا خير الهزاده'، مهدى عليز اده زارعى"'، مالك امينى'، فائزه دهقان طرزجانى}

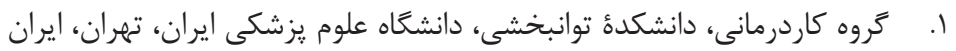

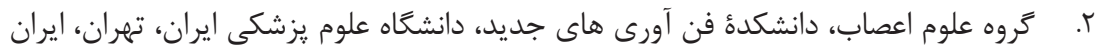

\begin{tabular}{|c|c|}
\hline جكيده & اطلاعات مقاله \\
\hline 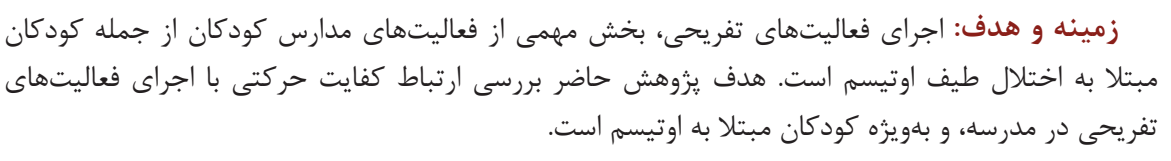 & $\begin{array}{ll}\text { تاريخ وصول: } & \text { تاريخ يُشار آنلاين: }\end{array}$ \\
\hline 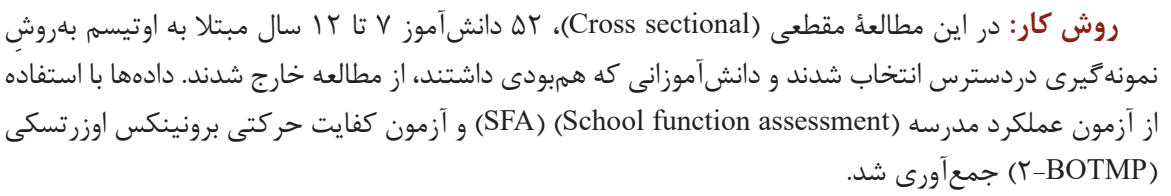 & نويسندهُ مسئول: \\
\hline 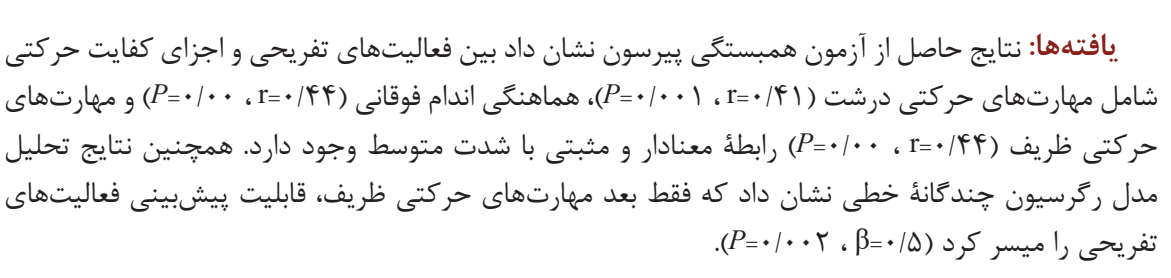 & 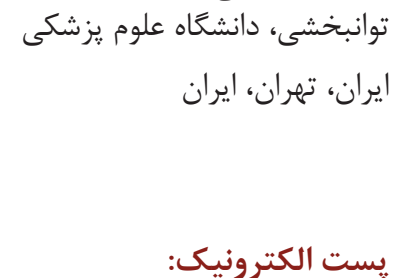 \\
\hline 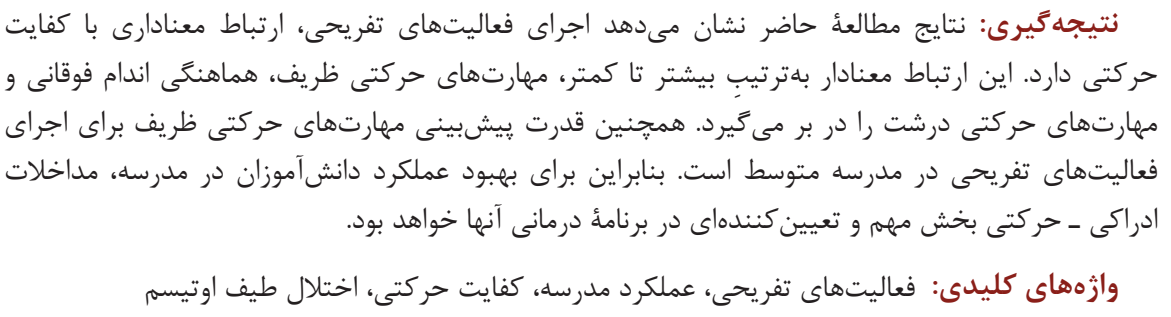 & تلفن: \\
\hline
\end{tabular}

